\title{
Photons and electrons for the study of a white veil covering some walls in prehistoric caves
}

\author{
Rémy Chapoulie ${ }^{1}$, Léna Bassel ${ }^{1}$, Guilhem Mauran ${ }^{1}$, Catherine Ferrier ${ }^{2}$, Alain Queffelec ${ }^{2}$, Delphine \\ Lacanette ${ }^{3}$, Philippe Malaurent ${ }^{3}$, Bruno Bousquet ${ }^{4}$, Vincent Motto-Ros ${ }^{5}$, Florian Trichard ${ }^{5}$, Frédéric \\ Pelascini $^{6}$, Vincent Rodriguez ${ }^{7}$
}

${ }^{1}$ IRAMAT-CRP2A, UMR CNRS 5060, Université Bordeaux Montaigne, Maison de l'Archéologie, Domaine Universitaire, Esplanade des Antilles, 33607 Pessac Cedex, France

${ }^{2}$ PACEA, UMR CNRS 5199, Université de Bordeaux, Bâtiment B8, Allée Geoffroy Saint Hilaire, CS 50023, 33615 Pessac Cedex, France

${ }^{3}$ I2M, UMR 5295 CNRS, Université de Bordeaux, 33607 Pessac, France

${ }^{4}$ CELIA, UMR CNRS 5107, Université de Bordeaux, 351 Cours de la Libération, 33405 Talence Cedex, France

${ }^{5}$ Institut Lumière Matière, UMR 5306, Université de Lyon 1 - CNRS, Université de Lyon, 69622 Villeurbanne Cedex, France

${ }^{6}$ CRITT Matériaux Alsace, 19 rue de St Junien, C. S. 80023, 67305 Schiltigheim, France

${ }^{7}$ ISM, UMR CNRS 5255, Université de Bordeaux, 351 Cours de la Libération, 33405 Talence Cedex, France

\begin{abstract}
Our research deals with the evolution of wall surfaces in prehistoric caves. The focus of this paper is dedicated to the physico-chemical characterization of a white concretion partially covering some walls in caves. In one of the caves, a non-ornate one which became a laboratory-cave (the Leye cave at Marquay, Dordogne, France) located in the Vézère valley, a set of physical methods has been proposed and tested on the first samples taken: SEM-EDXS, cathodoluminescence and laser-based techniques such as Raman spectroscopy and LIBS. Thus two different facies mainly composed of calcium carbonate crystals have been determined. The identification of theses crystalline phases is the first step of an ambitious research project that plans to understand the development of unexpected layers on the cave walls of the famous ornate caves listed as part of the UNESCO cultural heritage sites. This first set of data provides good insight to the physico-chemical composition and structure of the involved materials. Future works will be dedicated to bring knowledge about the facies chronology, the climatic conditions of environment (temperature, $\mathrm{CO}_{2}$ rate and air velocities) over a long period.
\end{abstract}

\section{Section: RESEARCH PAPER}

Keywords: white veil; archaeometry; taphonomy; prehistoric caves

Citation: Rémy Chapoulie, Léna Bassel, Guilhem Mauran, Catherine Ferrier, Alain Queffelec, Delphine Lacanette, Philippe Malaurent, Bruno Bousquet, Vincent Motto-Ros, Florian Trichard, Frédéric Pelascini, Vincent Rodriguez, Photons and electrons for the study of a white veil covering some walls in prehistoric caves, Acta IMEKO, vol. 6, no. 3, article 13, September 2017, identifier: IMEKO-ACTA-06 (2017)-03-13

Section Editor: Sabrina Grassini, Politecnico di Torino, Italy

Received May 30, 2017; In final form August 3, 2017; Published September 2017

Copyright: (C) 2017 IMEKO. This is an open-access article distributed under the terms of the Creative Commons Attribution 3.0 License, which permits unrestricted use, distribution, and reproduction in any medium, provided the original author and source are credited

Funding: This work was supported by the Région Nouvelle-Aquitaine, the cluster of excellence LaScArBx Laboratoire des sciences archéologiques de Bordeaux (ANR-10-LABX-52), the CNRS, and the universities of Bordeaux Montaigne and Bordeaux

Corresponding author: Rémy Chapoulie, e-mail: chapoulie@u-bordeaux-montaigne.fr

\section{INTRODUCTION}

In the South West of France, the Vézère valley represents a famous region of prehistoric caves. This region is indeed rich with ornate caves; either painted or engraved, and represents therefore an area where rock art cave conservation is an important issue. Curators are faced with different kinds of calcitic coatings on the walls that make the underlying rock art disappear. For instance this is the case at Rouffignac cave in Dordogne (see Figure $1 \mathrm{left}$ ). In the present study, we focused on two types of alterations characterized by two types of facies. The first one is the so-called calcitic moonmilk, described by the presence of thin needle fiber calcite, which is frequently 


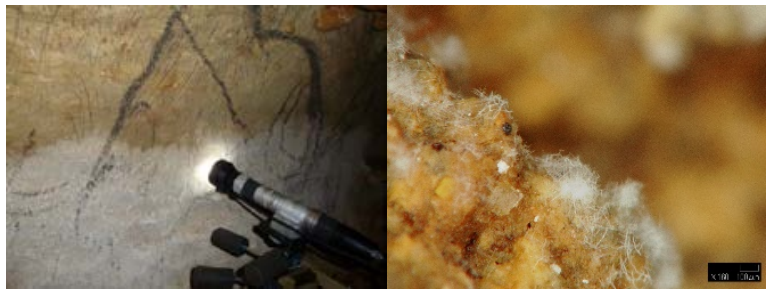

Figure 1. Left: optical microscope at Rouffignac cave lighting a moonmilk layer. Right: calcite needles seen at magnification 160 (scale bar shows 100 microns) at Combarelles cave

found in caves and has already been extensively studied [1]-[4]. The second one, referred as coralloid, presents a pop-corn like aspect [2]. In order to investigate the mechanisms responsible for the genesis and development of such concretions, a cave without any archaeological relevance and containing both moonmilk and coralloid types of concretions, has been selected since 2008 along the Vézère valley area to become a laboratorycave [5]. The Leye cave is thus considered to be representative of the ornate cavities from the area from both morphological and geological aspects.

This paper shows the first data (observations and analyses) obtained from the first samples taken out from this laboratorycave, that enabled to determine the two facies and their chemical composition and structure. The methods used were chosen in this aim: optical microscope for observing the moonmilk which seems rather homogeneous at first sight, Scanning Electron Microscopy for the identification of calcite needles in the moonmilk at micron scale, and the methods for chemical composition (X Ray Fluorescence, Raman and Laser Induced Breakdown Spectroscopy) mainly for the coralloid which were analyzed at the surface and in cross-section. Also used is the Cathodoluminescence method to know about the presence of impurities and point defects in the coralloid structure.

\section{METHODS AND DATA}

All methods did not show significant results on the two facies. So only the relevant data are shown here.

\subsection{Optical and electronic methods for observation}

While the coralloids were rather easy to recognize by sight (see Figure 4), optical microscopy was required to reveal the presence of needles in moonmilk. The mobile optical microscope used was a VCR-800 Hirox type with maximum magnification of 400, LED lighting and CCD camera. Figure 1 shows the instrument at Rouffignac cave and some calcite needles picture taken at Combarelles cave also located in Dordogne, France.

SEM-EDXS was used to provide not only images but also analytical data. Samples have been observed by electron microscopy in various modes using a JEOL JSM-6460LV linked to an Oxford Instrument X max Energy Dispersive XRay Spectrometer (EDXS). Two samples from the Leye cave were gold-coated and observed in high vacuum. These samples were chosen due to their high diversity of elements of biological origin and of needle fiber calcite shape [6].

Macroscopic differences can be seen between the samples from the laboratory-cave but no clear trend about microscopic differences on the structure of the biominerals [1] can be highlighted. All the different kinds of needles were observed on the biomineral samples. Each sample presented a large variability in the needles' morphology. Figure 2 presents the different habits, while Figure 3 presents the variability of the needle fiber calcite and of the epitaxial needles from different samples.

Cathodoluminescence imaging was only performed on the cross-section of a coralloid sample (Figure 4); it was of no use

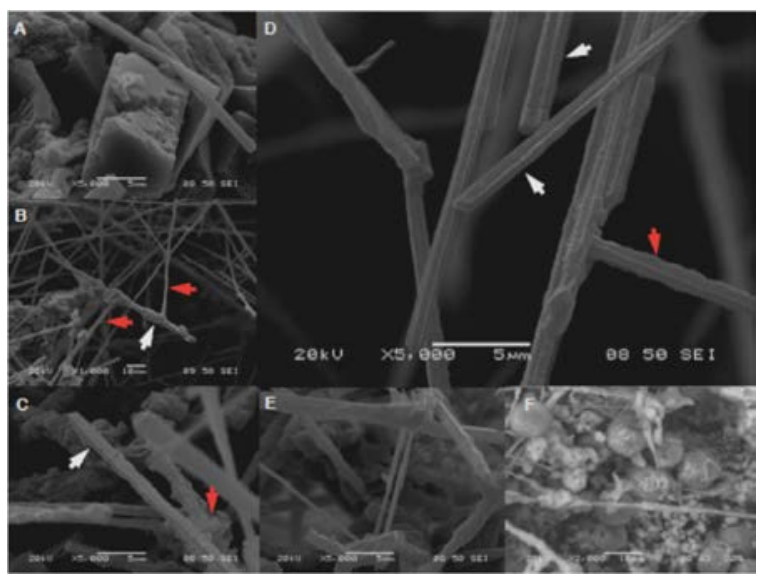

Figure 2. (A) to (F) SEM-Secondary Electron Image mode of some carbonated habits. (A) Broken needle fiber calcite lying on a corroded carbonate mineral. (B) Whiskers chain (white arrow) linked by epitaxial needles (red arrows). (C) Typical needle-fiber calcite with serrated edges (white arrows), epitaxial nodule (red arrows). (D) Typical paired needle fiber calcite without serrated edges (white arrows), needle-fiber calcite with serrated edges (red arrow). (E) Nanofiber and small bacteria. (F) calciumrich spheroids and epitaxial needles.

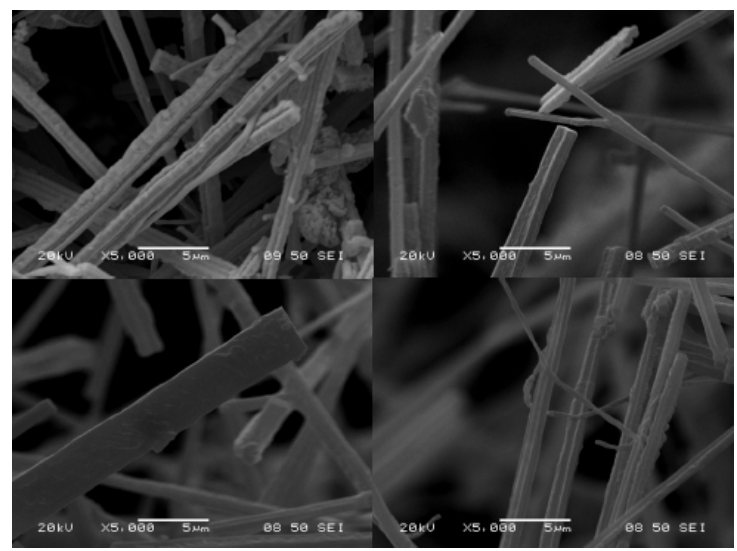

Figure 3. SEM-Secondary Electron Image mode showing the variability of the needle fiber calcite and of the epitaxial needles.

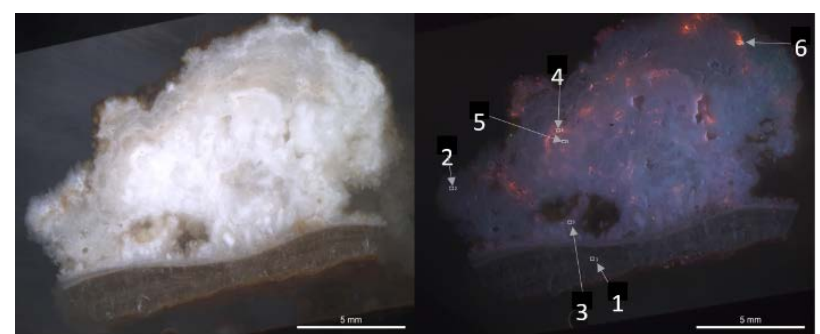

Figure 4. Cathodoluminescence imaging of a coralloid. Left: white-light imaging of the cross-section. Right: cathodoluminescence imaging of the same cross-section with a dark blue layer made of calcite (spot 1), a light blue for the coralloid (spots 2, 3, 5), and an orange emission from the laminae fronts (spots 4 and 6). Spot 5 is also analyzed by Raman spectroscopy (see Figure 9). 
on the moonmilk sample which could not be prepared as crosssection. The experiment was carried out with a Luminoscope system producing an electron beam accelerated by $10 \mathrm{kV}$, wide enough to observe the luminescence emission on a large area $(10 \times 15 \mathrm{~mm})$. With this method, the luminescent centers are revealed under the electron beam impact [7]. Blue luminescence is to be linked to the presence of calcite carbonate defect at $\mathrm{CO}_{3}$ group. Here (Figure 4 right) a dark blue layer can be seen covering the bedrock. A lighter and more intense blue comes out of the main part of the coralloid while the smaller orange areas reveal the presence of low concentrations in manganese preferentially located at the laminae fronts.

\subsection{Photonic methods and results}

Two portable systems were used. A pXRF (x-SORT from Ametek-SPECTRO) showed the obvious presence of calcium as major and the presence of iron and strontium in low amounts for both moonmilk and coralloids (Figure 5). A noticeable difference appears for $\mathrm{Sr}$ which is between 4 to 10 times more abundant in coralloids. Non-contact measurements were also tested and it was proved that a $4 \mathrm{~mm}$ distance from the wall was still performant whenever a tripod was set, which is relevant for cave art studies.

With a portable LIBS equipment (EasyLIBS from IVEA Solution) the chemical elements detected for the moonmilk and the coralloids were: $\mathrm{Mg}, \mathrm{Si}, \mathrm{Fe}, \mathrm{Al}, \mathrm{Sr}$ and $\mathrm{Ca}$. It is noticeable that $\mathrm{Mg}$ and $\mathrm{Sr}$ intensities were much higher in coralloids than in moonmilk. So far it should be also noticed that strontium and magnesium were considered as elements of major interest in the composition of speleothems [8]-[10]. Actually, the presence of strontium is directly linked to the growth rate of speleothems and was consequently used as an indicator of the growth speed [8]. Strontium is also probably more favorable to the orthorhombic aragonite structure than to the rhomboedric calcite structure when precipitation occurs [8] while magnesium is considered to be a good indicator of hydrology in the caves and to be responsible for the inhibition of calcite growth [8] [11]. This direct LIBS analysis $(8 \mathrm{~cm}$ from the wall surfaces with our equipment) gave access to this list of elements detected on the surface of the coralloid. A specific attention was paid to the coralloids. Figure 6 shows some of them spread as white concretions on the cave walls. The sampling area is clearly visible in this image and part of the extracted coralloid is shown in Figure 6b.

Analyzing the sample along a cross-section was necessary to enhance our understanding of genesis and growth. Thus, seventeen LIBS measurements were performed with the

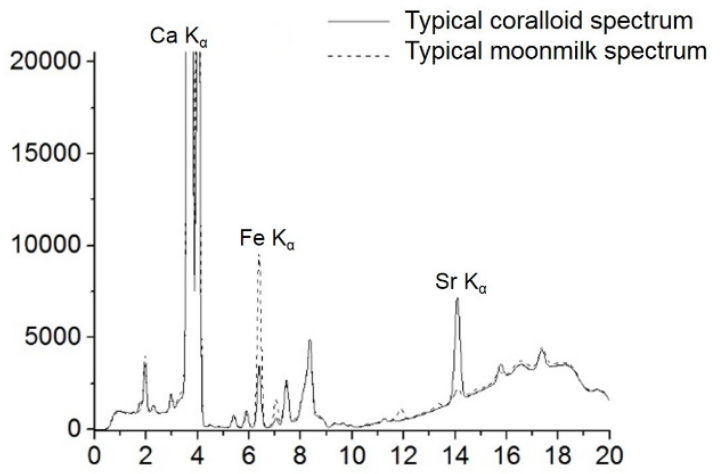

Figure 5. Typical XRF spectra from moonmilk and coralloid showing the presence of $\mathrm{Ca}$, Fe and $\mathrm{Sr}$.

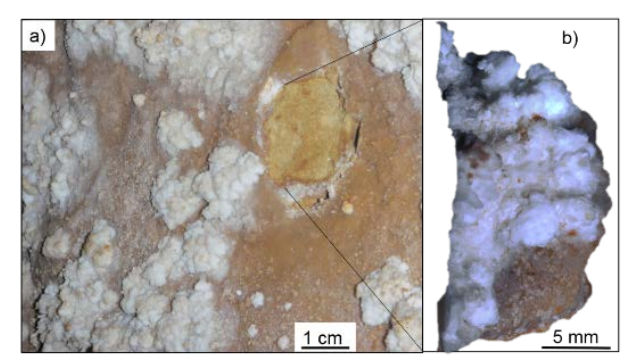

Figure 6. Coralloid sample from laboratory-cave (after [17]). a) Picture of a cave wall from the laboratory-cave covered by coralloids showing the sampling area; b) Zoom in on the coralloid extracted from the wall.

portable instrument along a transect axis aligned with the growth direction, as described in Figure 7 . The spacing between two LIBS analyses was fixed to $0.5 \mathrm{~mm}$ and the location of the transect was arbitrarily chosen. From figure 7 , three different layers can be clearly seen: the underlying bedrock, a brownish layer that we will call internal layer and an external layer appearing whitish, which is the final surface layer of the wall. Thus, this in-depth profiling allowed highlighting the variation of the LIBS signals related to strontium and magnesium. These first pLIBS data are better illustrated in the mapping picture (Figure 8).

Indeed this cross-section was additionally scanned by benchtop LIBS (Figure 8). The instrument used to provide the LIBS images has been described in [12] and [13] (laser source was a Nd:YAG emitting $8 \mathrm{~ns}$ pulses at $1064 \mathrm{~nm}$ with a $100 \mathrm{~Hz}$ repetition rate; laser energy was reduced at typically $1.5 \mathrm{~mJ}$; laser pulses were focused onto the sample by a $15 \times$ magnification objective resulting in a crater size close to $8 \mu \mathrm{m}$ ). The spatial distributions of $\mathrm{Mg}$ and $\mathrm{Sr}$ were found to be rather similar in the external layer (Figure 8a and 8c). The intensity ratio between the external and the internal layer is close to 3 for $\mathrm{Mg}$ (Figure 8a) and close to 7 for $\mathrm{Sr}$ (Figure 8c). It was demonstrated that the presence of $\mathrm{Sr}$ and $\mathrm{Mg}$ in the cave waters was mainly due to bedrock dissolution [14]. Our data are in line with this statement since on all the images presented in Figure 8 , the underlying host rock which is calcareous in the laboratory cave contains all the elements detected in the external layer. Soil leakage could also have played a role in the presence of $\mathrm{Sr}$ as revealed by isotopic data [15], [16]. Even though, it is remarkable that the internal layer seems to be more depleted in the elements of interest. This could be the result of migration of the elements from the base of the coralloid to the external limit in contact with air. Indeed, this internal layer appears to be made of calcite crystals.

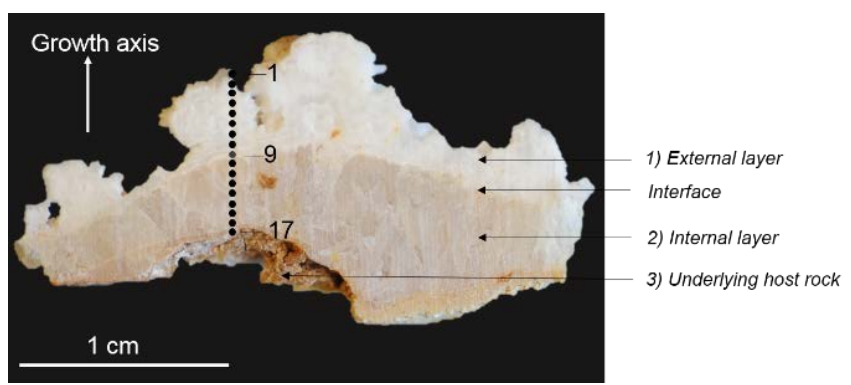

Figure 7. Cross-section of coralloid and location of the transect along which 17 LIBS measurements were performed (black circles). Three phases were identified as external layer (1), internal layer (2) and underlying host rock (3) (after [17]). 

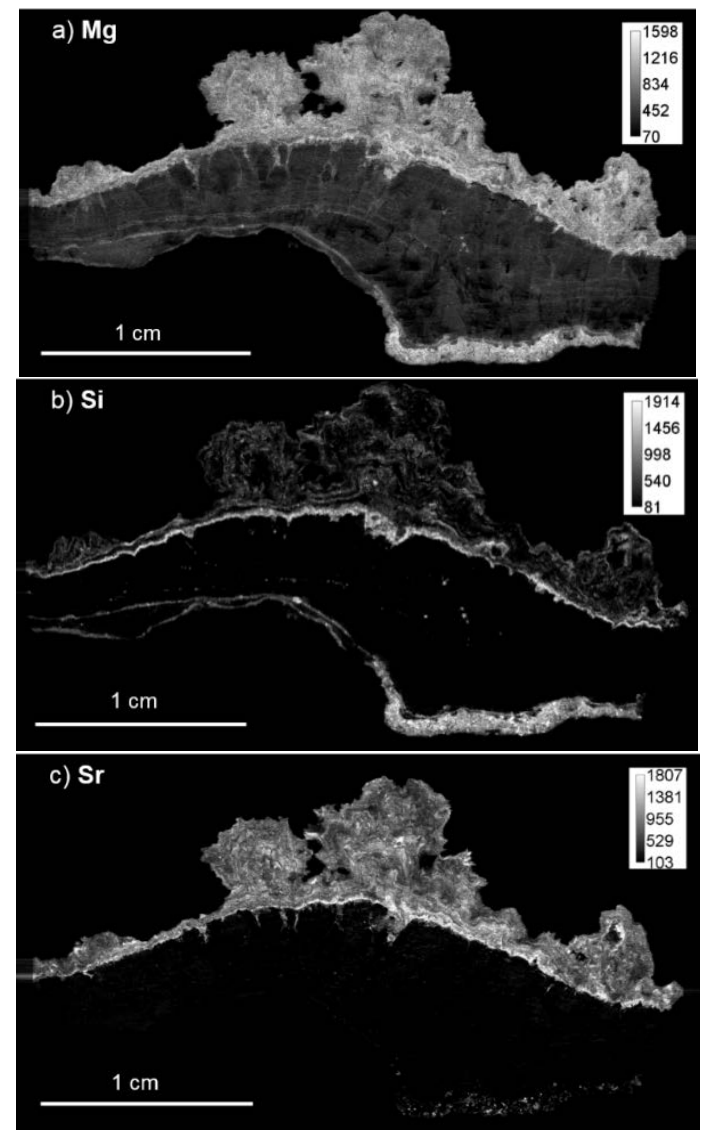

Figure 8. Elemental images of a coralloid sample by LIBS (after [17]). a) Mg image at $285.21 \mathrm{~nm}$; b) Si image at $288.16 \mathrm{~nm}$; c) Sr image at $407.77 \mathrm{~nm}$. The intensity signal displayed corresponds to the raw emission signal after background subtraction. Intensity threshold calibration bars display the minimum value in black corresponding to the background level and the maximum value in white.

Regarding the spatial distribution of the LIBS signal of $\mathrm{Si}$ (Figure $8 \mathrm{~b}$ ), it particularly reflects the presence of a series of laminations linked to higher LIBS signal of Si. The fact that laminations were observed is not surprising since it is consistent with the supposed formation process by successive precipitation events at the interface with the ambient air of the cave. The high contrast in LIBS signal of Si observed at the interface between the two layers suggests the presence of a detrital clay interface richer in Si than the calcium carbonate around it [17].

Raman spectroscopy was also carried out with an Xplora confocal Raman microscope from Horiba Scientific (objective $20 \times, \mathrm{NA}=0.32$ ), using a $785 \mathrm{~nm}$ laser excitation in order to minimize luminescence drawbacks. It enabled to distinguish the stable phases of calcium carbonates: aragonite and calcite. Specific peaks were identified and a mapping (Figure 9) was performed. Figure 9 corresponds to the area of spot 5 in Figure 4 right; it shows the localization of aragonite surrounded by crystals of calcite.

\section{CONCLUSIONS}

The major achievements of the research presented in this manuscript are the identification of the two facies of calcium carbonates found in this cave, a laboratory-cave which is quite similar to the famous caves of the Vézère Valley in Dordogne, France.

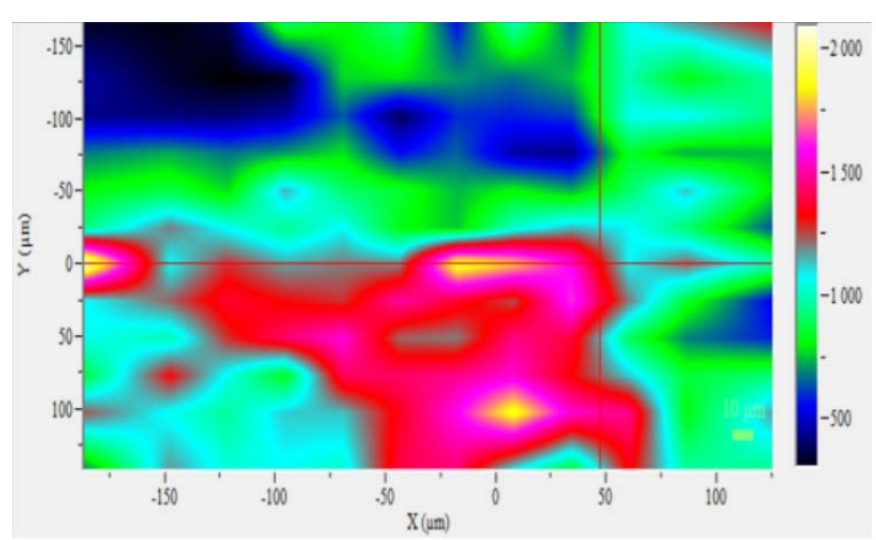

Figure 9. Raman mapping $\left(\sim 300 \times 300 \mu \mathrm{m}^{2}\right)$ using the ratio of $210 \mathrm{~cm}^{-1}$ aragonite peak $/ 280 \mathrm{~cm}^{-1}$ calcite peak. Spot diameter is ca $2.5 \mathrm{um}$. Red, pink

The moonmilk concretions were identified with SEM thanks to their morphology. It is noticeable to mention that optical microscopy can show their presence at high magnification because of their needle structure.

For coralloids, both calcite and aragonite were formally identified thanks to Raman spectroscopy in their classical habitus : massive for calcite and fibrous for aragonite. Their location can thus be studied by means of Raman cartography.

The chemical composition of coralloids was defined by LIBS. The LIBS and CL methods confirmed the laminae structure. This structure indicates many phases of interactions between the surface of the wall and the ambient air.

These methods bring us important data that should be crossed with others such as environmental and chronological ones (in progress) to reach out our main objective of understanding the origin and growth kinetics of these calcitic facies.

\section{ACKNOWLEDGEMENTS}

This work was supported by the Région Nowvelle-Aquitaine, the French State managed by the French National Research Agency within the framework of the cluster of excellence Laboratoire des sciences archéologiques de Bordeaux (ANR-10-LABX-52), the CNRS, and the universities of Bordeaux Montaigne and Bordeaux. Special thanks to Mister Delbos and his family for allowing us to go and work in the laboratory-cave at Marquay, Dordogne, France.

\section{REFERENCES}

[1] E. P. V. K. E. Verrecchia, (1994). Needle-fiber calcite: a critical review and a proposed classification. J of Sediment Res 64(3).

[2] C. A. Hill, and P. Forti (1997). Cave minerals of the world, National speleological society.

[3] A. Borsato, S. Frisia, B. Jones, K. Van der Borg (2000). Calcite moonmilk: Crystal morphology and environment of formation in caves in the Italian alps. J Sed Res 70(5), pp. 1179-1190.

[4] S. Sanchez-Moral, M. C. Portillo, I. Janices, S. Cuezva, A. Fernández-Cortés, J. C. Cañaveras and J. M. Gonzalez (2012). The role of microorganisms in the formation of calcitic moonmilk deposits and speleothems in Altamira Cave. Geomorphology 139-140, pp. 285-292.

[5] D. Lacanette, D. Large, C. Ferrier, N. Aujoulat, F. Bastian, A. Denis, V. Jurado, B. Kervazo, S. Konik, R. Lastennet, P. Malaurent and C. Saiz-Jimenez (2013). A laboratory cave for the study of wall degradation in rock art caves: an implementation in the Vézère area. J Archaeol Sci 40(2), pp. 894-903. 
[6] J.C. Cañaveras, S. Sanchez-Moral, V. Soler, and C. Saiz-Jimenez (2001). Microorganims and microbially induced fabrics in cave walls. Geomicrobiology Journal, 18, pp. 223-240.

[7] S. Cazenave, R. Chapoulie , G. Villeneuve (2003). Cathodoluminescence of synthetic and natural calcite: the effects of manganese and iron on orange emission. Mineralogy and Petrology 78, no 3, pp. 243-253.

[8] I. J. Fairchild, A. Baker, A. Borsato, S. Frisia, R. W. Hinton, F. McDermott, A. F. Tooth (2001). Annual to sub-annual resolution of multiple trace-element trends in speleothems (English). J Geol Soc London 158(5), pp. 831-841.

[9] A. Borsato, S. Frisia, I. J. Fairchild, A. Somogyi and J. Susini (2007). Trace element distribution in annual stalagmite laminae mapped by micrometer-resolution X-ray fluorescence: Implications for incorporation of environmentally significant species. Geochim Cosmochim Ac 71(6), pp. 1494-1512.

[10] D. J. Sinclair, J. L. Banner, F. W. Taylor, J. Partin, J. Jenson, J. Mylroie, E. Goddard, T. Quinn, J. Jocson and B. Miklavič (2012). Magnesium and strontium systematics in tropical speleothems from the Western Pacific. Chem Geol 294-295, pp. $1-17$.

[11] W. White (2012). Speleothem microstructure/speleothem ontogeny: a review of Western contributions. Int J of Speleol 41(2), pp. 329-358.
[12] V. Motto-Ros, E. Negre, F. Pelascini, G. Panczer and J. Yu (2014). Precise alignment of the collection fiber assisted by realtime plasma imaging in laser-induced breakdown spectroscopy. Spectrochim Acta B 92, pp. 60-69.

[13] L. Sancey, V. Motto-Ros, B. Busser, S. Kotb, J. M. Benoit, A. Piednoir, F. Lux, O. Tillement, G. Panczer and J. Yu (2014). Laser spectrometry for multi-elemental imaging of biological tissues. Sci Rep 4: 6065 (7p).

[14] I. J. Fairchild, C. L. Smith, A. Baker, L. Fuller, C. Spötl, D. Mattey, F. McDermott and E.I.M.F (2006). Modification and preservation of environmental signals in speleothems. Earth Sci Rev 75(1-4) pp. 105-153.

[15] I. J. Fairchild, P. C. Treble (2009). Trace elements in speleothems as recorders of environmental change. Quaternary Sci Rev 28(56) pp. 449-468.

[16] C. Bourdin, E. Douville, D. Genty (2011). Alkaline-earth metal and rare-earth element incorporation control by ionic radius and growth rate on a stalagmite from the Chauvet Cave, Southeastern France. Chem Geol 290(1-2) pp. 1-11.

[17] L. Bassel, V. Motto-Ros, F. Trichard, F. Pelascini, F. Ammari, R. Chapoulie, C. Ferrier, D. Lacanette and B. Bousquet (2016). Laser-Induced Breakdown Spectroscopy for elemental characterization of calcitic alterations on cave walls. Environ. Sci. Pollut. Res. 1-8; DOI 10.1007/s11356-016-7468-5. 